\title{
Preoperative body mass index and outcomes of gastric cancer patients
}

\author{
Kyoji Ogoshi' ${ }^{1)}$, Kaichi Isono ${ }^{2)}$ \\ ${ }^{1)}$ Department of Surgery, Tokai University, ${ }^{2)}$ President of Chiba University
}

\begin{abstract}
Background: The influence of lower body mass index on the survival in cancer patients has not been fully estimated. While, many studies suggest that body mass index were positively associated with an increased risk of cancers of the esophagus, colon, gallbladder, pancreas, breast, endometrium, kidney, and ovary, so the rapid growth in the prevalence of obesity as new threats foretells health problems in years to come.

Methods: We assessed preoperative body mass index (BMI) of 2677 patients with malignant and benign diseases who enrolled in the data base for The Japanese Society of strategies of Cancer research and Therapy from May 1975 to February 2004, for evaluating how BMI effect on the outcomes of patients, with examining some parameters.

Results: During the period of this study from 1975-, the median BMI increased from $21.6 \mathrm{~kg} / \mathrm{m}^{2}, 21.9 \mathrm{~kg} / \mathrm{m}^{2}, 21.9 \mathrm{~kg} / \mathrm{m}^{2}$, and $22.2 \mathrm{~kg} / \mathrm{m}^{2}$, to $22.4 \mathrm{~kg} / \mathrm{m}^{2}$. Serum gastrrin levels, T-IGR, SA, IAP, and CEA were increased significantly than those in both normal and obesity patients. The 10-year-survival rates (disease specific death) of patients of underweight, normal, overweight, and obese were 38.0 (52.0) \%, 58.7 (69.5) \%, 68.5 (77.4) \%, and 54.3 (62.6) \%, respectively. (Fig. 3 left) There were significant differences among these groups. (Underweight vs. normal, overweight, and obese, $\mathrm{p}<0.001, \mathrm{p}<0.001$, and $\mathrm{p}=0.042$. normal vs. overweight, $\mathrm{p}<0.001$ )

Conclusions: We found that underweight as well as obese not but overweight patients were shown poor survival rates, and that underweight group showed older persons with lower acid output, higher gastrinemia, higher serum levels of IAP, sialic acid, and CEA than normal weight and overweight group. These findings of this study suggest that underweight group also alterations in growth factors and acute phase reactants. This needs to be investigated in other samples and populations.
\end{abstract}

Key Words: Gastric cancer, preoperative body mass index (BMI), outcomes of patients

(Received June 13, 2005; Accepted August 30, 2005)

\section{Introduction}

The recent overweight and obesity people rise calls the governments' attentions in the world to be important in health care to reduce body weight. Obesity raises the risk for chronic conditions ranging from diabetes to dementia, and many studies suggest that body mass index were positively associated with an increased risk of cancers of the esophagus, colon, gallbladder, pancreas, breast, endometrium, kidney, and ovary ${ }^{1)}$. So the rapid growth in the prevalence of obesity as new threats foretells health problems in years to come. Even in the Japanese the percentages of body mass index $>30$ in adult were increased from $2 \%$ in 1980 to $3 \%$ in 2001 , while, from $15 \%$ in $1976-1980$ to $31 \%$ in $1999-2000$ in USA. (http://www.oecdtokyo.org/theme/health/2004/ 20040603healthdata.html, http://www.mhlw.go.jp/houdou/2002/12/h1211-1b3.html)

Correspondence to: Kyoji Ogoshi, Department of Surgery, Yokai University, 143 Shimokasuya, Isehara, Kanagawa, 259-1193 Japan
On the other hand, the relationship between excess body weight and mortality, not only from all causes but also from cardiovascular disease, are well established ${ }^{2-7)}$.

The aim of this study was to describe the 30-year changes in body mass index (BMI; $\mathrm{kg} \mathrm{m}^{-2}$ ) and the relation between the BMI and the outcomes in Japanese patients with malignant diseases.

\section{Materials and Methods}

We assessed preoperative body mass index (BMI) of 2677 patients with malignant and benign diseases who enrolled in the data base for The Japanese Society of Strategies of Cancer Research and Therapy from May 1975 to February 2004, for evaluating how BMI effect on the outcomes of patients. The BMI was calculated as the weight in kilograms divided by the square of the height in meters $\left(\mathrm{kg} / \mathrm{m}^{2}\right)$, and was categorized according to the NIH Guidelines' cutoff points, i.e., underweight, less than $18.5 \mathrm{~kg} / \mathrm{m}^{2}$, normal, from 18.5 to $24.9 \mathrm{~kg} / \mathrm{m}^{2}$, overweight, 25.0 to $29.9 \mathrm{~kg} / \mathrm{m}^{2}$ and obese $30 \mathrm{~kg} / \mathrm{m}^{2}$ or more (National Heart, Lung, and Blood Institute, 1998). 


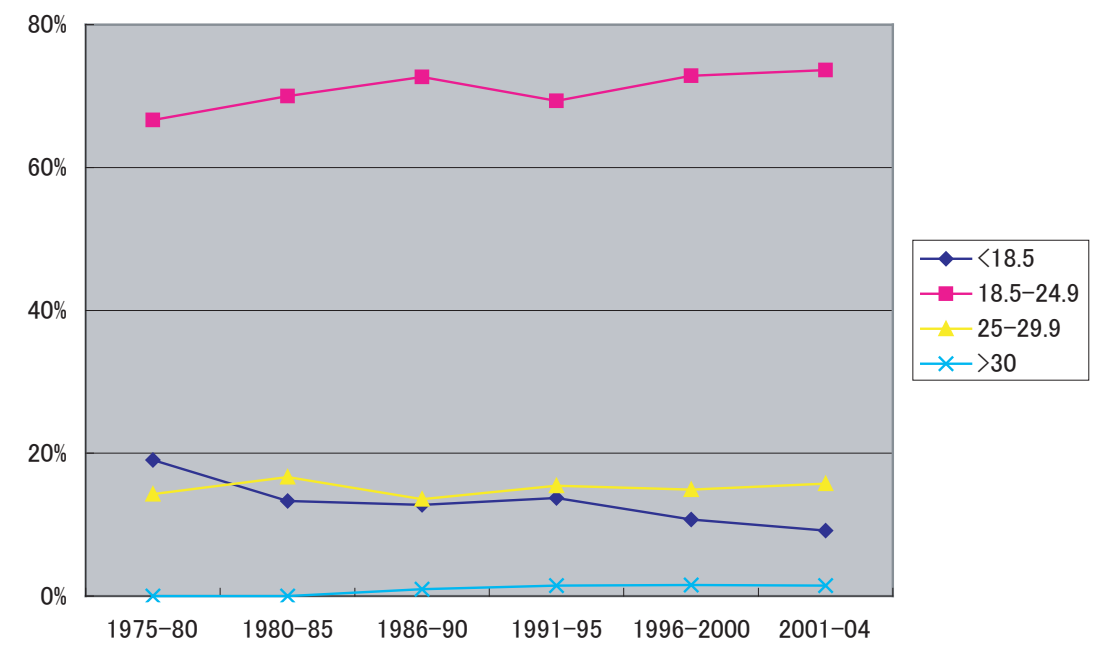

Fig. 1 The time trends of BMI during the period from 1975 to 2004.

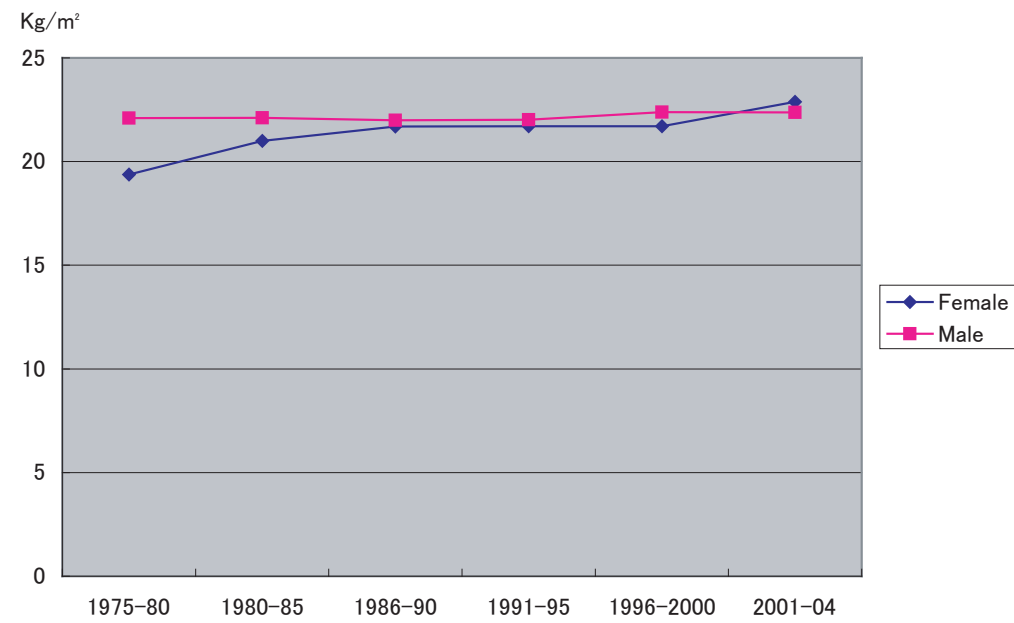

Fig. 2 The time trends of BMI during the period from 1975 to 2004 in male and female.

In Japanese cases, in general, there were three groups, i.e., underweight, less than $18.5 \mathrm{~kg} / \mathrm{m}^{2}$, normal, from 18.5 to $24.9 \mathrm{~kg} / \mathrm{m}^{2}$, obesity, $25.0 \mathrm{~kg} / \mathrm{m}^{2}$ or more.

Among them, CD4, CD8, and CD4/8 as immunological makers $(n=1624)$, pepsinogen $(\mathrm{PG}) 1$ and 2 as atrophic gastritis makers $(n=851)$, basic acid output (BAO), maximal acid output (MAO) $(n=576)$, serum gastrin levels $(n=578)$ as gastric function, and serum immunosuppressive acidic glycoprotein (IAP) $(\mathrm{n}=1681)^{8}$, sialic acid (SA) $(n=1690)^{9)}$, and carcinoembryonic antigen (CEA) $(n=1353)$ as tumor markers were examined. This examination method was revealed in other papers.

\section{Statistical analysis}

Mean values were compared by Student's t-test. We used the chi-square test to compare the prevalence of characteristics. Results were considered significant when the 2-tailed P-value was less than 0.05. Survival curves were calculated using the Kaplan-Meier product-limit es- timate, and differences in survival were assessed by the log-rank test. P-values of less than 0.05 were considered to be significant. All statistical analyses were carried out using SPSS 13.0 software (SPSS, Inc., Chicago, IL, USA).

\section{Result}

\section{Time trend of BMI}

During the period of this study from 1975-, the median BMI increased from $21.6 \mathrm{~kg} / \mathrm{m}^{2}, 21.9 \mathrm{~kg} / \mathrm{m}^{2}, 21.9$ $\mathrm{kg} / \mathrm{m}^{2}$, and $22.2 \mathrm{~kg} / \mathrm{m}^{2}$, to $22.4 \mathrm{~kg} / \mathrm{m}^{2}$ (1986-1990 vs. 1996-2000, 2001-, $\mathrm{p}=0.03, \mathrm{p}=0.026$, respectively.) (Fig. 1). The mean BMI slightly increased in men with an increment of $+0.27 \mathrm{~kg} / \mathrm{m}^{2}$, while in women, by $+3.52 \mathrm{~kg}$ $\mathrm{m}^{2}$ (Fig. 2).

\section{BMI status in Japan}

The Average of BMI of patients with gastric cancer, colorectal cancer, double cancer, and others cancers, and 


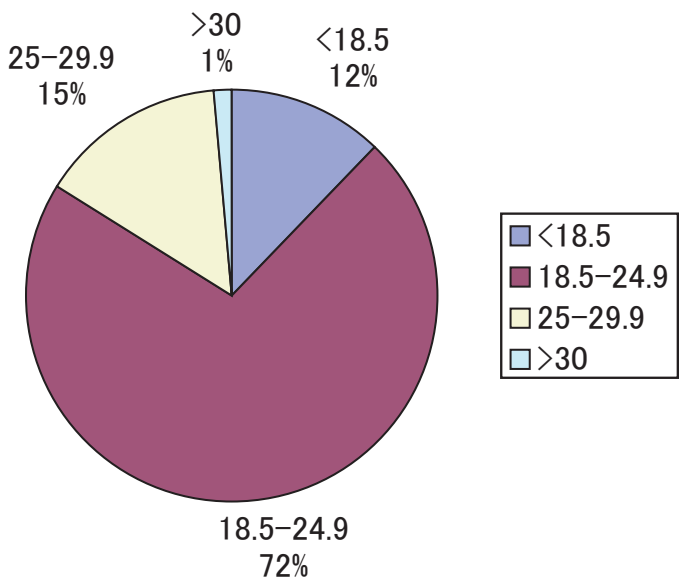

Fig. 3 BMI status in Japan.

Table 1 Clinical papameters according to the BMI stata.

\begin{tabular}{|c|c|c|c|c|c|c|c|c|c|c|c|c|c|}
\hline & & & & & Body M & ass Ind & (BMI & $\left(\mathrm{kg} / \mathrm{m}^{2}\right)$ & & & & & Stastistics \\
\hline & & $<18.5$ & & & $18.5-24$. & & & $25-29.9$ & & & $>30$ & & \\
\hline & $\mathrm{n}$ & mean & SD & $\mathrm{n}$ & mean & SD & $\mathrm{n}$ & mean & SD & $\mathrm{n}$ & mean & SD & \\
\hline Age & 329 & 63.0 & 13.5 & 1928 & 60.5 & 11.7 & 394 & 60.1 & 10.7 & 35 & 60.3 & 12.2 & $a: p=0.001, b: p=0.001$ \\
\hline $\mathrm{CD} 4 / 8$ & 212 & 1.9 & 0.9 & 1165 & 1.9 & 0.8 & 228 & 1.9 & 0.8 & 19 & 1.7 & 0.7 & \\
\hline CD 4 & 212 & 44.4 & 9.5 & 1165 & 45.0 & 9.5 & 228 & 44.7 & 9.9 & 19 & 42.4 & 8.3 & \\
\hline CD 8 & 212 & 26.9 & 8.0 & 1165 & 27.0 & 8.0 & 228 & 26.5 & 7.5 & 19 & 29.1 & 10.8 & \\
\hline PG I/II & 103 & 2.7 & 2.0 & 610 & 2.8 & 1.6 & 127 & 3.0 & 1.9 & 11 & 2.2 & 1.1 & \\
\hline PG I & 103 & 59.5 & 70.0 & 610 & 55.2 & 46.7 & 127 & 53.7 & 43.5 & 11 & 36.6 & 31.0 & \\
\hline PG II & 103 & 23.1 & 21.3 & 610 & 21.7 & 20.9 & 127 & 19.4 & 14.3 & 11 & 16.4 & 8.1 & \\
\hline BAO & 82 & 0.6 & 1.4 & 391 & 1.0 & 2.2 & 94 & 1.2 & 2.3 & 9 & 0.5 & 1.1 & \\
\hline MAO & 82 & 3.5 & 4.3 & 391 & 5.4 & 6.8 & 94 & 5.6 & 6.0 & 9 & 4.7 & 7.2 & $\mathrm{a}: \mathrm{p}=0.017, \mathrm{~b}: \mathrm{p}=0.011$ \\
\hline Gastrin & 83 & 86.2 & 108.5 & 388 & 62.8 & 93.1 & 98 & 59.9 & 69.6 & 9 & 49.5 & 34.5 & $\mathrm{a}: \mathrm{p}=0.045$ \\
\hline T-IGR & 83 & 3.7 & 1.3 & 388 & 3.3 & 1.2 & 98 & 3.1 & 1.2 & 9 & 3.4 & 1.1 & $\mathrm{a}: \mathrm{p}<0.0001, \mathrm{~b}: \mathrm{p}=0.001$ \\
\hline IAP & 213 & 504.0 & 273.1 & 1220 & 433.4 & 190.8 & 237 & 426.8 & 171.7 & 20 & 382.6 & 195.0 & $\mathrm{a}: \mathrm{p}<0.0001, \mathrm{~b}: \mathrm{p}<0.0001$ \\
\hline SA & 211 & 63.1 & 16.4 & 1214 & 59.6 & 14.0 & 236 & 60.2 & 11.7 & 20 & 62.5 & 15.7 & $a: p=0.001, b: p=0.029$ \\
\hline CEA & 185 & 17.5 & 105.6 & 967 & 5.7 & 22.6 & 182 & 12.6 & 89.2 & 19 & 5.7 & 13.3 & $a: p=0.002, c: p=0.036$ \\
\hline & & & & & & & & & & & & & $\begin{array}{l}\text { a:BMI }<18.5 \text { vs BMI } 18.5-24.9 \\
\text { b:BMI }<18.5 \text { vs BMI } 25-29.9 \\
\text { c:BMI } 18.5-24.9 \text { vs } 25-29.9\end{array}$ \\
\hline
\end{tabular}

benign diseases were $22.1 \mathrm{~kg} / \mathrm{m}^{2}, 22.2 \mathrm{~kg} / \mathrm{m}^{2}, 21.7 \mathrm{~kg} / \mathrm{m}^{2}$, and $22.3 \mathrm{~kg} / \mathrm{m}^{2}$, and $21.2 \mathrm{~kg} / \mathrm{m}^{2}$, respectively. There was no significant difference among them. The proportion of underweight, normal, overweight, and obese patients was $12.2 \%(n=326), 71.8 \%(n=1922), 14.7 \%(n=394)$, and $1.3 \%(n=35)$ of patients (Fig. 3).

\section{BMI and other parameters}

Immunological makers such as CD4, CD8, and CD4/8, atrophic gastritis makers such as Pep1, 2, and $1 / 2$ ratio, did not show significant differences between groups of BMI. On the other hand, MAO in the underweight patients was decreased significantly than that in both normal and obesity patients. Serum gastrin levels, T-IGR, SA, IAP, and CEA were increased significantly than those in both normal and obesity patients (Table 1).

\section{BMI and the outcomes in patients}

The 10-year-survival rates (disease specific death) of patients of underweight, normal, overweight, and obese were $38.0(52.0) \%, 58.7(69.5) \%, 68.5(77.4) \%$, and 54.3 (62.6) \%, respectively. (Fig. 4 left) There were significant differences among these groups. (underweight vs. normal, overweight, and obese, $\mathrm{p}<0.001, \mathrm{p}<0.001$, and $\mathrm{p}=0.042$. normal vs. overweight, $\mathrm{p}<0.001$ ).

The survival curves of patients of underweight, normal, obesity, and obese were shown in Fig. 4 (right). There were significant differences among underweight, normal, and obesity groups. (underweight vs. normal vs. obesity, all is $\mathrm{p}<0.001)$.

In the cases of gastric cancer, there were significant better survival in stage 1A (underweight vs. normal and obesity, $\mathrm{p}<0.001$ ), and in stage 2 (underweight vs. normal and obesity, $\mathrm{p}<0.009, \mathrm{p}=0.038$, respectively) (Fig. 5).

\section{BMI and cause of death}

In patients of underweight, normal, overweight, and obese group 145 (44.5\%), 564 (29.3\%), 82 (20.8\%), and $11(31.4 \%)$ were died by cancers, respectively, while 33 (10.1\%), 114 (5.9\%), 17 (4.3\%), and 1 (2.9\%) were died 

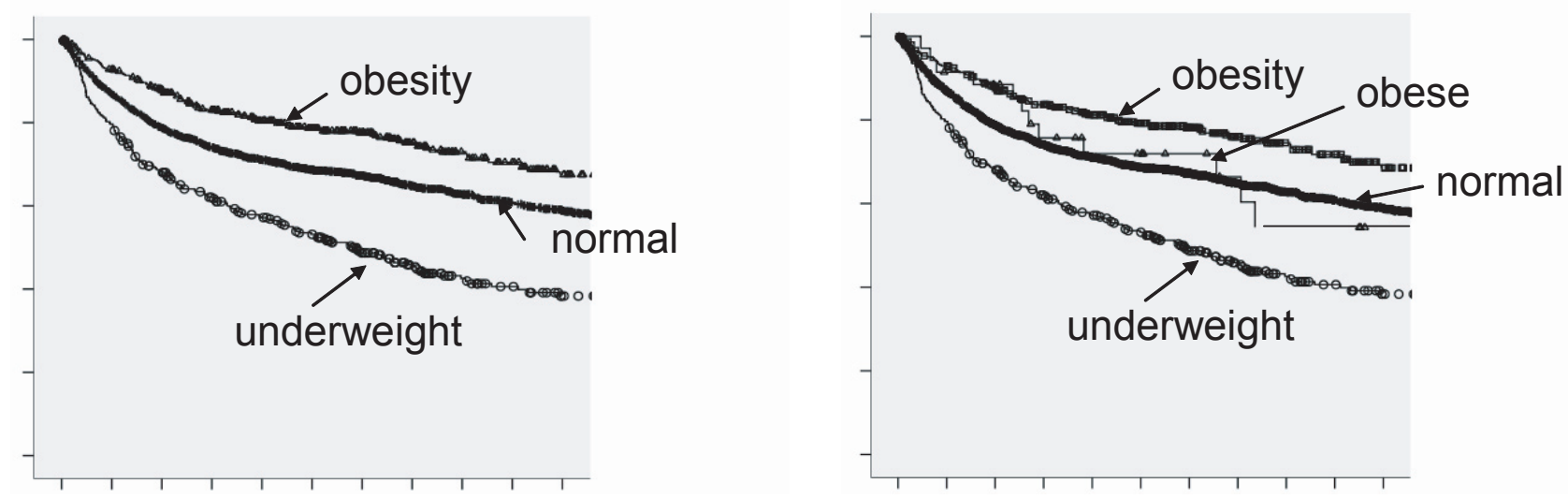

Fig. 4 Survival cureves according to the patients with underweight, normal, and obesity (left), and those with underweight, normal, obesity, and obese (right).

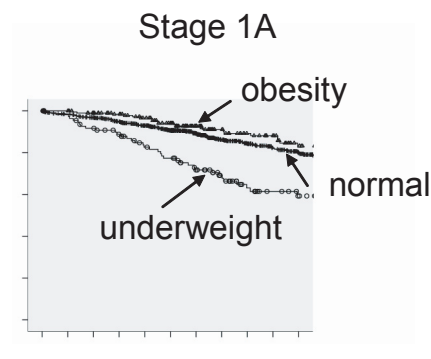

Stage $3 \mathrm{~A}$

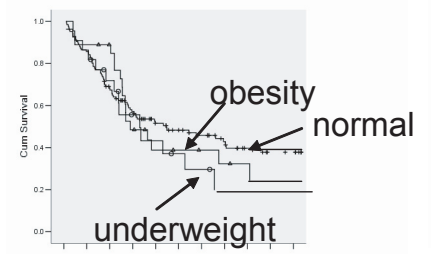

Fig. 5 Survival curves of gastric cancer patients according to the PTNM stages and BMI stata.
Stage 1B

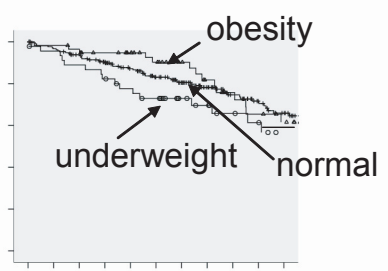

Stage 3B

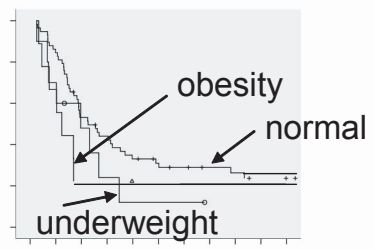

Stage 2

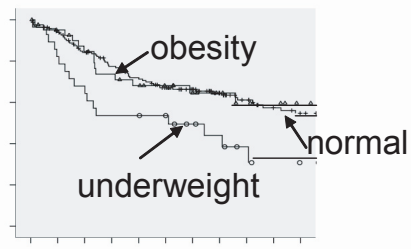

Stage 4

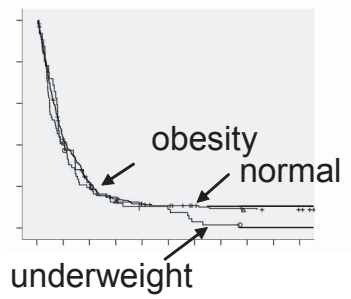

by benign diseases, respectively (Fig. 6).

\section{Discussion}

In the case of Japan, a decreasing trend of mean BMI was most significant in the female 20-29 years age-group $\left(-0.38 \mathrm{~kg} / \mathrm{m}^{2} / 10\right.$ years $)$, in contrast to an increasing trend observed in elderly women (60-69 and 70+ years age-groups). This is the discrepancy between Japan and the West countries; the number of overweight and obese people has increased in the west countries where researchers could not assess the relationship between underweight BMI and outcomes of the patients, while that of underweight has increased in Japan where researchers could not assess the relationship between higher BMI and outcomes of obese patients. In general, obesity is also a known risk factor for diseases such as diabetes, hypertension, cardiovascular diseases, respiratory problems (asthma), musculoskeletal diseases (arthritis), as well as cancers. Therefore, this increase is a new threat in the world, after dramatic reduction of smoking, leading to a decline in the incidence of lung cancer. In both men and women, body-mass index was also significantly associated with higher rates of death due to cancer of the esophagus, colon and rectum, liver, gallbladder, pancreas, and kidney; the same was true for death due to non-Hodgkin' s lymphoma and multiple myeloma. Significant trends of increasing risk with higher body-mass-index values were observed for death from cancers of the stomach and prostate in men and for death from cancers of the breast, uterus, cervix, and ovary in women. But, little is known about the relationship between preoperative underweight BMI value and outcomes among cancer patients after treatment. Nomura et al. reported ${ }^{10)}$ that Body mass in$\operatorname{dex}\left(\mathrm{BMI}=\right.$ weight $/$ height $\left.^{2}\right)$ at time of examination and weight gain since age 25 were positively associated with 


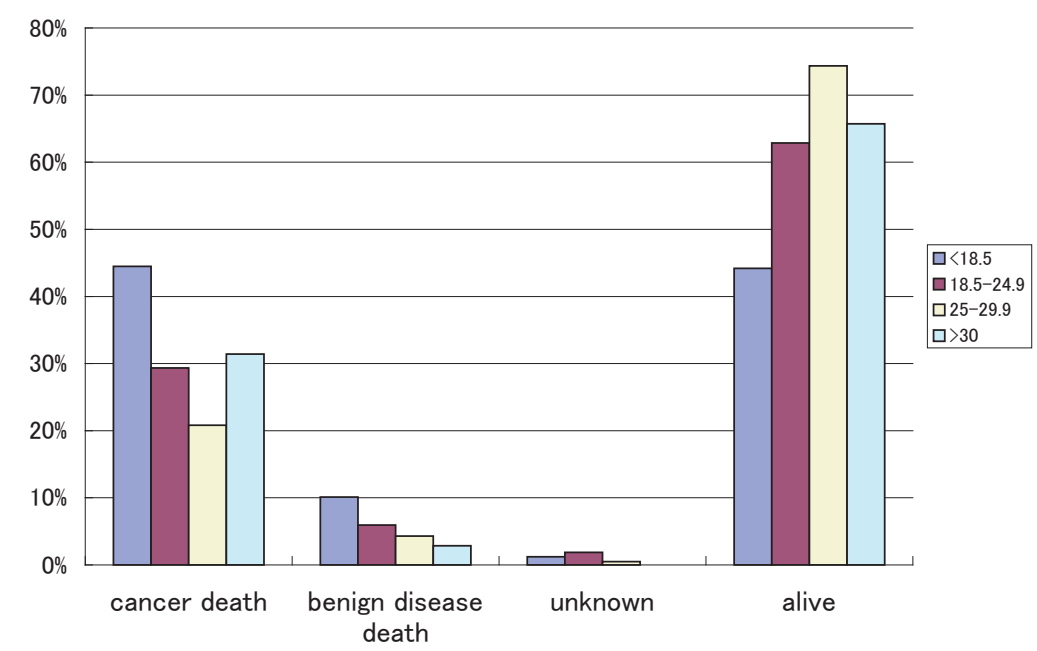

Fig. 6 Cause of death according to the BMI stata.

an increased risk for colon cancer in subjects age 55 or older at the time of examination. Weight losses since age 25 were associated with an increased risk for stomach cancer, whereas only weight loss since age 25 was associated with an increased risk for lung cancer. These two cancers accounted for the overall significant association of weight loss with total cancer incidence. We found that under weight as well as obese not but overweight patients were shown poor survival rates.

On the other hand, Weisberg et al ${ }^{11)}$ reported that adipose tissue macrophage numbers increase in obesity and participate in inflammatory pathways that are activated in adipose tissues of obese individuals. These results suggested that the macrophage content of adipose tissue correlated positively with two indices of adiposity: BMI and adipocyte size, and also that the relationship between adipose tissue macrophage content and indicators of adiposity provides a mechanism for the increased adipose tissue production of proinflammatory molecules and acute-phase proteins associated with obesity. Lambert et al., reported found a strong relationship between CRP concentration and BMI as early as age $9^{12)}$. Immunosuppressive acidic protein (IAP) which was examined in this study was reported by Tamura et al. ${ }^{13)}$ as a glycoprotein containing $31.5 \%$ carbohydrates with a molecular weight of 50,000 and a single acidic isoelectric point of 3.0. It has been described a new subfraction of the acute phase reactant alpha- 1 acid glycoprotein ${ }^{14)}$ and suppresses both phytohemagglutinin induced lymphoblast formation and mixed lymphocyte reaction in vitro. Gastrin acted as an autocrine growth factor ${ }^{15}$.

There were several potential mechanisms by which obesity could lead to several cancers included alterations in sex hormones (e.g., estrogen, progesterone, and androgens), and insulin and IGF-1 in obese people that may account for their increased risk for cancers of the breast, endometrium, and colon. Sex-hormone binding globulin, the major carrier protein for certain sex hormones in the plasma, may also be involved in the altered risk for these cancers in obese people ${ }^{16-19)}$.

We found that underweight group showed older persons with lower acid output, higher gastrinemia, higher serum levels of IAP, sialic acid, and CEA than normal weight and overweight group. These findings of this study suggest that underweight group also alterations in growth factors and acute phase reactants. This needs to be investigated in other samples and populations.

\section{Reference}

1) Vainio, H. and Bianchini, F. (2002). IARC handbooks of cancer prevention. Volume 6: Weight control and physical activity. Lyon, France: IARC Press.

2) Calle, E.E., Rodriguez, C., Walker-Thurmond, K. and Thun, M.J. (2003). Overweight, Obesity, and Mortality from Cancer in a Prospectively Studied Cohort of U.S. Adults. N. Engl. J. Med. 348: 1625-1638.

3) Willett, W.C., Manson, J.E., Stampfer, M.J., Colditz, G.A., Rosner, B., Speizer, F. E., Hennekens, C. and Weight, H. (1995). Weight change, and coronary heart disease in women: risk within the "normal' weight range. JAMA. 273: 461-465.

4) Stevens, J., Plankey, M.W., Williamson, D.F., Thun, M.J., Rust, P.F., Palesch, Y. and O'Neil, P.M. (1998). The body mass index-mortality relationship in white and African American women. Obes. Res. 6: 268-277.

5) Lindsted, K.D. and Singh, P.N. (1998). Body mass and 26 y risk of mortality among men who never smoked: a re-analysis of men from the Adventist Mortality Study. Int. J. Obes. Relat. Metab. Disord. 22: 544-548.

6) Calle, E.E., Thun, M.J., Petrelli, J.M., Rodriguez, C. and Heath, C.W. Jr. (1999). Body-mass index and mortality in a prospective cohort of U.S. adults. N. Engl. J. Med. 341: 1097-1105.

7) Kopelman, P. (2000). Obesity as a medical problem. Nature. 404: 635-643.

8) Ogoshi, K., Miyaji, M., Iwata, K., Kondoh, Y., Tajima, T. and Mitomi, T. (1992). Splenectomy, immunosuppressive acidic protein and postoperative immunotherapy in gastric cancer patients with total or proximal gastrectomy; a multivariate analysis. Ann Cancer Res Ther, 1: 61-66.

9) Ogoshi, K., Kondoh, Y., Tajima, T. and Mitomi, T. (1992). Glycosidically bound sialic acid levels as a predivtive marker of postoperative adjuvant therapy in gastric cancer. Cancer Immuno. 
Immunother. 35: 175-180.

10) Nomura, A., Heilbrun, L.K. and Stemmermann, G.N. (1985). Body mass index as a predictor of cancer in men. J. Natl. Cancer Inst. 74: 319-323.

11) Weisberg, S.P., McCann, D., Desai, M., Rosenbaum, M., Leibel, R.L. and Ferrante, Jr. A.W. (2003). Obesity is associated with macrophage accumulation in adipose tissue. Clin. Invest. 112: 1796-1808.

12) Lambert, M., Delvin, E.E., Paradis, G., O’Loughlin, J., Hanley, J.A. and Levy, E. (2004). C-Reactive Protein and Features of the Metabolic Syndrome in a Population-Based Sample of Children and Adolescents. Clin. Chem. 50: 1762-1768.

13) Tamura, K., Shibata, Y., Matsuda, Y. and Ishida, N. (1981). Isolation and characterization of an immunosuppressive acidic protein from ascetic fluids of cancer patients. Cancer Res. 41: 3244-3252.

14) Van Oss, C.J. and Bronson, P.M. (1974). Isolation and purification of human serum alpha-1 acidic glycoprotein. Preparative Biochemistry. 4: 115-126.

15) Dockray, G., Dimaline, R. and Varro, A. (2005). Gastrin: old hormone, new functions. Pflug. Arch. Eur. J. Physiol. 449: 344-355.

16) Bianchini, F., Kaaks, R., and Vainio, H. (2002). Overweight, obesity, and cancer risk. Lancet Oncol. 3: 565-574.

17) Key, T.G., Appleby, P.N., Reeves, G.K., Roddam, A., Dorgan,
J.F., Longcope, C., Stanczyk, F.Z., Stephenson, Jr. H.E., Falk, R.T., Miller, R., Schatzkin, A., Allen, D.S., Fentiman, I.S., Wang, D.Y., Dowsett, M., Thomas, H.V., Hankinson, S.E., Toniolo, P., Akhmedkhanov, A., Koenig, K., Shore, R.E., Zeleniuch-Jacquotte, A., Berrino, F., Muti, P., Micheli, A., Krogh, V., Sieri, S., Pala, V., Venturelli, E., Secreto, G., Barrett-Connor, E., Laughlin, G.A., Kabuto, M., Akiba, S., Stevens, R.G., Neriishi, K., Land, C.E., Cauley, J.A., Kuller, L.H., Cummings, S.R., Helzlsouer, K.J., Alberg, A.J., Bush, T.L., Comstock, G.W., Gordon, G.B. and Miller, S.R. (2003). Body mass index, serum sex hormones, and breast cancer risk in postmenopausal women. J. Natl. Cancer Inst. 95: 1218-1226.

18) Amling, C.L., Riffenburgh, R.H., Sun, L., Moul, J.W., Lance, R.S., Kusuda, L., Sexton, W.J., Soderdahl, D.W., Donahue, T.F., Foley, J.P., Chung, A.K. and McLeod D.G. (2004). Pathologic variables and recurrence rates as related to obesity and race in men with prostate cancer undergoing radical prostatectomy J. Clin. Oncol. 22: 439-445.

19) Freedland, S.J., Aronson, W.J., Kane, C.J., Presti, Jr. J.C., Amling, C.L., Elashoff, D. and Terris M.K. (2004). Impact of Obesity on Biochemical Control After Radical Prostatectomy for Clinically Localized Prostate Cancer: A Report by the Shared Equal Access Regional Cancer Hospital Database Study Group. J. Clin. Oncol. 22: 446-453. 